\title{
Focussed antenatal care a possible opportunity towards safe motherhood
}

\author{
Sunkad M. A. ${ }^{1 *}$ Rajeshwari Kadakol $^{2}$, Darshit Shetty ${ }^{2}$, Javali S. B. ${ }^{1}$, Satish Dhamankar ${ }^{2}$
}

\begin{abstract}
${ }^{1}$ Department of Community Medicine, ${ }^{2}$ Department of Obstetrics and Gynaecology, School of Medical Sciences,
\end{abstract} USM-KLE-International Medical Program, Nehru Nagar, Belgaum, India

Received: 02 June 2019

Accepted: 09 July 2019

\section{*Correspondence:}

Dr. Sunkad M. A.

E-mail: mohan.sunkad@usmkle.edu.in

Copyright: () the author(s), publisher and licensee Medip Academy. This is an open-access article distributed under the terms of the Creative Commons Attribution Non-Commercial License, which permits unrestricted non-commercial use, distribution, and reproduction in any medium, provided the original work is properly cited.

\section{ABSTRACT}

Background: The Primary Health Care Setting gives a challenging opportunity for the clinicians to deal with pregnancy into favorable outcomes solely based on the clinical skills in view of innumerable socio-cultural-economic barriers. The Pregnant women make satisfactory progress- to full term, deliver with minimal morbidity, no loss of life and healthy baby-How to ensure? This is the objectives of our study. Suppose Obstetricians spare time, use checklist, Prioritize and provide care will it make any difference in saving mothers? Objectives: Describe in detail the process of Focused Antenatal Care as practiced in Primary Health Care setting and Minimize mortality and morbidity due to pregnancy by 25 percent from 169. (Maternal Mortality Rate (MMR 169).

Methods: This is a community based descriptive, prospective, cohort study about a group of pregnant women till their delivery, using multiple cluster random sampling of 251 high risk pregnant women and subsequent follow up over 3 months with focused care. Compilation of data and analysis using SPSS Version 20.

Results: Total Study participants 251 represented all the sections of target population with regard to socio-economic and cultural background. The participants attended FANC giving a response rate of $100 \%$. These participants had one or more risk factor. All but 10 participants attended 4 or more FANC clinic visits $241(96 \%)$. In these participants the commonest manageable morbid conditions are underweight (20\%), anaemia (14\%) preeclampsia (8\%), eclampsia $(2 \%)$ and gestational diabetes. In our finding $87 \%$ mothers completed full term pregnancy, $11.5 \%$ preterm $(>28$ but $<$ 37 weeks) while $1.5 \%$ Post term. There were 241 live births, $87 \%$ Baby weight $>2.5 \mathrm{Kg}, 13 \%$ Baby weight $<2.5 \mathrm{Kg}$. with an average of $2.9 \mathrm{Kg}$.

Conclusions: We are able to describe the Focused ANC and able to help improve the quality of life and to minimize morbidity and mortality in pregnant women.

Keywords: Antenatal, Care, Focused, Healthcare, Primary

\section{INTRODUCTION}

The pregnancy is a natural physiological phenomenon. Every family has a woman of reproductive age on an average. Over the years health care delivery systems have taken great leap including care during pregnancy. The care of pregnant women is a basic element in Primary Health Care. Accordingly several initiatives have been taken to enlist pregnant women, engage them, educate them and motivate to utilize health care services while discouraging home births. The inclusion of improved maternal health as the fifth United Nations (UN) millennium development goal (MDG) in 2000, and specifying a reduction of three quarters in the maternal mortality ratio between 1990 and 2015 as the primary target of MDG has given thrust on governments to have proper systems to measure maternal mortality. We have come a long way. Our country is vast and diverse in 
cultural practices. The pregnancy is a common physiological event observed in a family. Our study area has one Primary Health Care Centre for every 6,000 families and one trained birth attendant for every 1,000 families. On an average 700 deliveries occur every year in this PHC area. The care of pregnant women (ANC) is an integral part of Primary Health Care centre and is being continued. The Basic Antenatal Care (ANC) has emphasis on number of visits and hence not so popular with only an average $50 \%$ of mothers attend. ${ }^{1-5}$ Over the years there have been so much socio cultural changes in the society and health care delivery system. Now we have adopted fully institutional deliveries by specialist birth attendants supported by free national ambulance service. However our maternal mortality rate still high at 130 . There has been an absolute or relative shortage of Obstetric specialists in the government sector and need for supplement from private sector under Public Private Partnership scheme. Hence we thought moving towards a qualitative approach of "Focused antenatal care" (FANC) as a possible intervention- a timely, friendly, simple, individualized care, safe service provided to pregnant women emphasizing her preparation for childbirth, readiness for complications, where to seek services if problems occur and enlisting the family in this process. ${ }^{6}$

\section{METHODS}

This is a community based descriptive, prospective, cohort study in a primary health care setting done during October 2016 to September 2018. The target population is area covered by Primary Health Care centre. The study participants are drawn from the pregnant women sampled from the sub centres. The inclusion criteria are Pregnant woman with high risk like bad obstetric history, willing to attend care, willing for the study. The exclusion criteria are pregnant women who migrate to other places, unable to attend the care and unwilling for study. The participants are identified by multiple cluster, systematic random sampling method, written consent obtained, collected data, prioritized the mothers, offered focused antenatal care, data compiled and analyzed using SPSS Version 20.

The routine procedure of institutional approval, written consent from participants obtained.

Focused antenatal care involves: four visits to obstetrician in 9 months period, monitor weight gain, HB percentage, Blood glucose level, Blood Pressure, Blood group, occurrence of pre eclamsia, eclampsia, sonographic scans and general nutrition status. Appropriate corrections made on identification.

Our resources are good functioning Primary Health Care Centre, group of village based activated women volunteers, availability of common drugs and always obliging, community oriented team of specialists in Obstetrics. Also willing participation of village women to avail these services has been our greatest asset.
Our primary step is identification of risk factor.

Followed by, treat infection, correct nutrition, keep watch on $\mathrm{Hb}$, keep track of changes of bp, keep track of weight gain, decide if satisfactory progress of pregnancy by simple score 0,1

Parameters included satisfactory weight gain, HB level maintained, adequate nutrition, BP within normal limits, no infection, blood sugar, foetal heart sounds, presentation, CPD, PP, etc., Readiness for delivery, Information support about SBA, Mobile contact, Financial support.

As for as possible establish Mobile contact for any support.

The checklist and Protocol scrupulously followed till the mother delivers and 2 months further for recovery.

Table 1: The final score.

\begin{tabular}{|lll|}
\hline $\begin{array}{l}\text { Score } \\
\text { Did the mother } \\
\text { reach full term? }\end{array}$ & Yes (Score 1) & No (Zero) \\
\hline $\begin{array}{l}\text { Did the mother } \\
\text { deliver live baby? }\end{array}$ & Yes (Score 1) & No (Zero) \\
\hline $\begin{array}{l}\text { Did the baby weigh } \\
\text { minimum 2.5 Kg? }\end{array}$ & Yes (Score 1) & No (Zero) \\
\hline $\begin{array}{l}\text { Did the mother suffer any morbid condition like } \\
\text { haemorrhage, anaemia, genital injury? }\end{array}$ & Yes (Zero) \\
\hline $\begin{array}{l}\text { Did we lose the } \\
\text { mother? }\end{array}$ & No (Score 1) & Yer \\
\hline
\end{tabular}

The strategies of engage, enlist, encourage, educate, examine, equip and enable the mothers for safe delivery has been followed. Our concentration is on the means and mother is our focus throughout.

\section{RESULTS}

Total Study participants 251 represented all the sections of target population with regard to socio-economic and cultural background. The participants gave their consent and attended FANC giving a response rate of $100 \%$. These participants have one or more risk factor like short stature, underweight, anaemia, history of abortion...etc., The average age of participants is 25 years with youngest 18 years, oldest 36 years for study. In these participants $105(41 \%)$ are primi gravida, $99(40 \%)$ are second gravida and $47(19 \%)$ are third and over with highest parity being 5. All but 10 participants attended 4 or more FANC clinic visits $241(96 \%)$ the remaining had abortion at $3^{\text {rd }}$ or $4^{\text {th }}$ month of pregnancy. In these participants the commonest manageable morbid conditions are underweight $(20 \%)$, anaemia (14\%) preeclampsia (8\%), eclampsia (2\%) and gestational diabetes. The pregnancy outcome is Normal Vaginal delivery in $66.5 \%$, Caesarian delivery in $26.5 \%$ and rest $4 \%$ Abortions. 
In this study finding $87 \%$ mothers completed full term pregnancy, $11.5 \%$ preterm (>28 but $<37$ weeks) while $1.5 \%$ Post term. There were 241 live births, $87 \%$ Baby weight $>2.5 \mathrm{Kg}, 13 \%$ Baby weight $<2.5 \mathrm{Kg}$. with an average of $2.9 \mathrm{Kg}$. The final FANC score maximum seen in 176 participants while 48 participants scored near maximum score.

Table 2: Age wise distribution of study participants.

\begin{tabular}{|lll|}
\hline Age group in years & Participants & Percentage \\
\hline$\leq 20$ & 34 & 14 \\
\hline $21-25$ & 129 & 51 \\
\hline $26-30$ & 71 & 28 \\
\hline$\geq 31$ & 17 & 8 \\
\hline Total & $\mathbf{2 5 1}$ & $\mathbf{1 0 0}$ \\
\hline
\end{tabular}

Table 3: Parity wise distribution of study participants.

\begin{tabular}{|lll|}
\hline Parity & Participants & Percentage \\
\hline First pregnancy & 105 & 41 \\
\hline Second Pregnancy & 99 & 40 \\
\hline$\geq$ Third Pregnancy & 47 & 19 \\
\hline Total & $\mathbf{2 5 1}$ & $\mathbf{1 0 0}$ \\
\hline
\end{tabular}

Table 4: FANC clinic attendance wise distribution of study participants.

\begin{tabular}{|lll|}
\hline FANC Clinic visit & Participants & Percentage \\
\hline First & 0 & 0 \\
\hline Second & 6 & 3 \\
\hline Third & 4 & 1 \\
\hline$\geq 4$ & 241 & 96 \\
\hline Total & $\mathbf{2 5 1}$ & $\mathbf{1 0 0}$ \\
\hline
\end{tabular}

Table 5: Morbid conditions identified and managed in the study participants.

\begin{tabular}{|lll|}
\hline $\begin{array}{l}\text { Morbid conditions } \\
\text { identified }\end{array}$ & Participants & Percentage \\
\hline Anaemia & 36 & 14 \\
\hline Pre-eclampsia & 20 & 8 \\
\hline Eclampsia & 5 & 2 \\
\hline Diabetes & 2 & 0.7 \\
\hline Underweight & 50 & 20 \\
\hline Normal & 138 & 55 \\
\hline Total & $\mathbf{2 5 1}$ & $\mathbf{1 0 0}$ \\
\hline
\end{tabular}

Table 6: Pregnancy outcome of study participants.

\begin{tabular}{|lll|}
\hline Pregnancy outcome & Participants & Percentage \\
\hline Abortion & 10 & 4.0 \\
\hline $\begin{array}{l}\text { Normal Vaginal } \\
\text { delivery }\end{array}$ & 165 & 66.5 \\
\hline $\begin{array}{l}\text { Caesarian Section } \\
\text { delivery }\end{array}$ & 76 & 29.5 \\
\hline Total & $\mathbf{2 5 1}$ & $\mathbf{1 0 0}$ \\
\hline
\end{tabular}

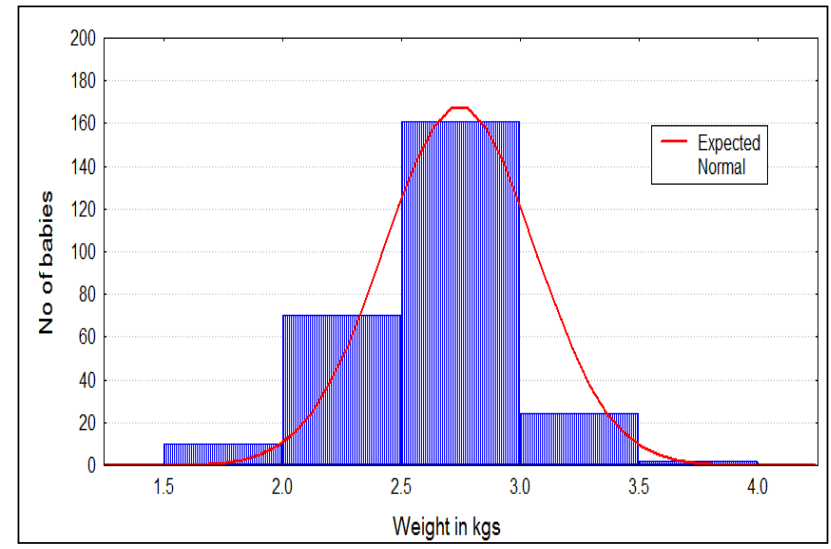

Figure 1: The distribution of baby weight at birth.

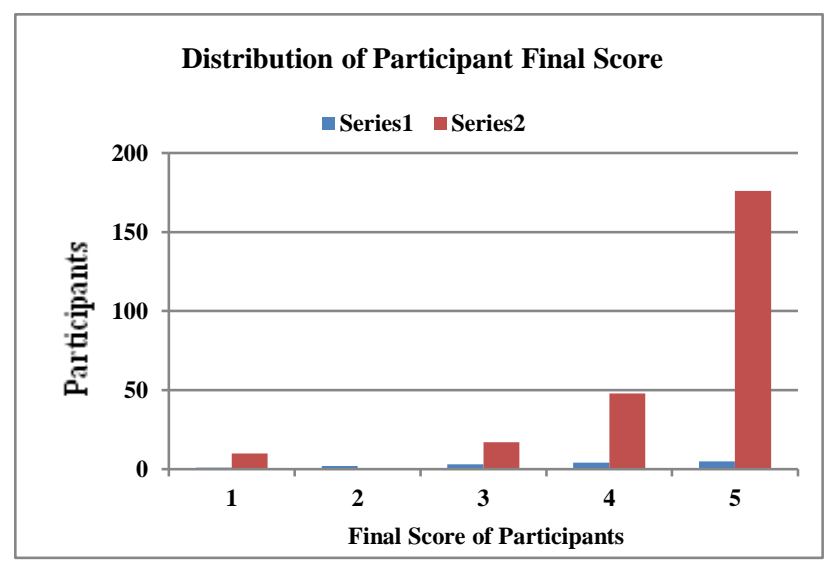

Figure 2: The final score of participants.

Table 7: The study participants, their pregnancy term and live birth wise distribution.

\begin{tabular}{|lll|}
\hline Term & No. of babies & \% of babies \\
\hline $\begin{array}{l}\text { Gestation week }>28 \\
\text { weeks <36 weeks }\end{array}$ & 28 & 11.40 \\
\hline $\begin{array}{l}\text { Normal gestation } \\
\text { week 37-41 weeks }\end{array}$ & 209 & 87.07 \\
\hline $\begin{array}{l}\text { Post term gestation } \\
\text { weeks 41 }\end{array}$ & 4 & 1.53 \\
\hline Total & $\mathbf{2 4 1}$ & $\mathbf{1 0 0 . 0 0}$ \\
\hline
\end{tabular}

Table 8: At birth, baby weight wise distribution.

\begin{tabular}{|c|c|c|}
\hline Weight at birth & $\begin{array}{l}\text { No. of } \\
\text { babies }\end{array}$ & $\begin{array}{l}\% \text { of } \\
\text { babies }\end{array}$ \\
\hline Baby weight $\leq 2.4 \mathrm{Kg}$ & 33 & 13.14 \\
\hline Mature baby weight at birth $\geq 2.5 \mathrm{Kg}$ & 208 & 86.85 \\
\hline Total & 241 & 100.00 \\
\hline
\end{tabular}

The telecommunication network in the study area is good. All the participants have simple Mobile phone set and familiar to use it, specifically 108 National Ambulance Service. Some participants 19\% have Smart phone set and able to use video call. They receive our call in $85 \%$ of time. 
Table 9: The participants and their final score distribution.

\begin{tabular}{|lll|}
\hline $\begin{array}{l}\text { Final score } \\
\text { (maximum 5) }\end{array}$ & $\begin{array}{l}\text { Number of } \\
\text { participants }\end{array}$ & Percentage \\
\hline 1 & 10 & 4 \\
\hline 2 & 0 & 0 \\
\hline 3 & 17 & 7 \\
\hline 4 & 48 & 19 \\
\hline 5 & 176 & 70 \\
\hline Total & $\mathbf{2 5 1}$ & $\mathbf{1 0 0}$ \\
\hline
\end{tabular}

\section{DISCUSSION}

Our Primary Health Care Centre is no different. It has shortage of resources. So are our participants having less health literacy, underweight, do not have adequate money and socially dependent on other to make health wise decision. On an average $30 \%$ women have trouble free pregnancy and child birth, another $30 \%$ have mild problems but bearable, easily manageable while another $35 \%$ need specialist assistance, need lot of care while remaining 5\% severe problems and complications that need constant attention for quite long time. There is a study done 10 years back in the same area finding $65 \%$ utilization of ANC care by mothers. ${ }^{7}$ Likewise cross sectional studies done in different parts of our country and across the globe report $25 \%$ to $72 \%$ utilization of Basic Antenatal Care services (ANC) with fair change in maternal morbidity and mortality. ${ }^{8-13}$ However our country average for maternal mortality remains at 130 .

Our approach in this study is Cohort, prospective over 3 years and Focused Antenatal Care (FANC). We have a representative sample drawn from all the area, age, parity in our study (Table 2, 3). We find a response rate $100 \%$ for participation, $96 \%$ for all 4 visits (Table 4). Some common maternal morbidity $14 \%$ mothers had severe anaemia, identified and managed timely, $8 \%$ had preeclampsia, were identified and managed, $2 \%$ had eclampsia, identified and managed, no mother suffered infection throughout the pregnancy period (Table 5).

The mothers who had normal vaginal delivery are $68.5 \%$ and Caesarian delivery $31.5 \%$ (Table 6). An average $88 \%$ of mothers are able to carry the pregnancy to full term (weeks 38-41) (Table 7) and an abortion rate 4\%. Most of the babies born have birth weight $\geq 2.5 \mathrm{Kg}$ (Table 8). Summarizing all the outcomes of the pregnancy we have given five point score and most mothers have scored well (Table 9). The average birth weight of new born is $2.9 \mathrm{Kg}$ (Figure 1). The Figure 2 gives ready distribution of Final Score of participants concerning pregnancy outcome. There were no episodes of excessive bleeding in any mother. There are two mothers with gestational diabetes, identified and managed.

In one of the studies there were healthcare delivery system barriers like-husband to accompany mother, small fee, registration paper, authorization letter from village head that impacted utilization of ANC services. ${ }^{14}$

In some studies they have reported literacy level of mother, her income, family background impacting utilization of FANC services. ${ }^{15-19}$

We are based in a teaching institution and volunteered to spare expertize, time and efforts to supplement the community. That is how this novel initiative over last three years. One solid community resource is presence of Accredited Social Health Activist (ASHA) in our study area, who can be a liaison between community and health care personnel. We organize every month educative programs (Garbha Chaitanya) for women on reproductive concerns.

We find good response from the women in these programs. There are occasions when in mothers may fail to attend the ANC Clinic then we can enquire their wellness through ASHA workers or make video call. Our health care personnel are aware, familiar and make use of Mother Child Tracking System. Perhaps these efforts are helpful to minimize barriers and sustain the attendance at the clinics. All these services are free of charges. Our study addressed socio-cultural-educational and economic factors by its friendly mode, hence $96 \%$ utilization of FANC services (Table 4). In the final score $89 \%$ of mother scored very well (Table 9).

The telecommunication network in the study area is good. All the participants have simple Mobile phone set and familiar to use it, specifically 108 National Ambulance Service. Some participants 19\% have Smart phone set and able to use video call. They receive our call in $85 \%$ of time.

Is it possible to reproduce this initiative in other place, perhaps the answer is "Yes", all that is needed is invitation and involvement of the community around.

\section{CONCLUSION}

Towards reducing the maternal mortality, morbidity Antenatal care is an essential tool. The basic antenatal care model faces barriers and focused antenatal care may perhaps be a viable alternative. Authors are able to give description of FANC and also minimize morbidity and mortality. Authors have meticulously concentrated on checklist and monitoring whatever we do in "Focused ANC.

\section{ACKNOWLEDGMENTS}

Authors would like to thank Dr. H. B. Rajashekhar, Director, Dr. S. C. Dharwad Director Clinical Services for permitting to spare our time. Authors are indebted to our team of Obstetrician colleagues Dr. Vidya Kakhandki, Dr. Ravindra Narsapur, Dr. Holikatti, Dr. Abhijit Deshpande for providing clinical service support 
throughout, Community Medicine colleagues who provided logistic support and ASHA Workers, staff of Primary Health Care Centre in cooperating with us all through last 3 years. Authors also remember and appreciate the willing participation of mothers in this study. Authors thank Ms. Shilpa, Ms. Hema, Mr. Dinesh for secretarial support in preparing this manuscript.

Funding: No funding sources

Conflict of interest: None declared

Ethical approval: The study was approved by the Institutional Ethics Committee

\section{REFERENCES}

1. Finlayson K, Downe S. Why do women not use antenatal services in low-and middle-income countries? A meta-synthesis of qualitative studies. PLoS medicine. 2013;10(1):e1001373.

2. Tolefac PN, Halle-Ekane GE, Agbor VN, Sama CB, Ngwasiri C, Tebeu PM. Why do pregnant women present late for their first antenatal care consultation in Cameroon?. Maternal health, neonatol and perinatol. 2017;3(1):29.

3. Islam MM, Masud MS- Determinants of frequency and contents of antenatal care visits in Bangladesh: Assessing the extent of compliance with the WHO recommendations. PLoS ONE. 13(9):e0204752.

4. Miltenburg AS, van der Eem L, Nyanza EC, van Pelt S, Ndaki P, Basinda N, Sundby J. Antenatal care and opportunities for quality improvement of service provision in resource limited settings: A mixed methods study. PloS one. 2017 Dec 13;12(12):e0188279

5. Moller AB, Petzold M, Chou D, Say L. Early antenatal care visit: a systematic analysis of regional and global levels and trends of coverage from 1990 to 2013. The Lancet Global Health. 2017;5(10):e97783.

6. Oshinyemi TE, Aluko JO, Oluwatosin OA. Focused antenatal care: Re-appraisal of current practices. International Nursing and Midwifery. 2018;10(8):908.

7. Metgud CS, Katti SM, Mallapur MD, Wantamutte AS. Utilization patterns of antenatal services among pregnant women: a longitudinal study in rural area of North Karnataka. Al Ameen J Med Sci. 2009;2(1):58-62.

8. MR NM, Siddalingappa H, Mishra B. Assessment of utilization of antenatal care services by mothers attending immunization sessions at a primary health centre in Mysore district, Karnataka, India. Int J Community Med Public Health. 2016;3(9):2561-5.

9. Kotresh M, Kumar P. Determinants of use of maternal health services in rural field practice area of basaveshwara medical college, Chitradurga: a cross sectional study. J Preventive Medicine and Holistic Health. 2015;1(2):59-66.

10. Ponna SN, Upadrasta VP, Geddam JB, Dudala SR, Sadasivuni R, Bathina $H$. Regional variation in utilization of Antenatal care services in the state of Andhra Pradesh. J family medicine and primary care. 2017;6(2):231.

11. Arunda M, Emmelin A, Asamoah BO. Effectiveness of antenatal care services in reducing neonatal mortality in Kenya: analysis of national survey data. Global health action. 2017;10(1):1328796.

12. Tikmani SS, Ali SA, Saleem S, Bann CM, Mwenechanya M, Carlo WA, Figueroa L, Garces AL, Krebs NF, Patel A, Hibberd PL. Trends of antenatal care during pregnancy in low-and middleincome countries: Findings from the Global Network Maternal and Newborn Health Registry. InSeminars in perinatol. WB Saunders. 2019.

13. Kuhnt J, Vollmer S. Antenatal care services and its implications for vital and health outcomes of children: evidence from 193 surveys in 69 lowincome and middle-income countries. BMJ open. 2017;7(11):e017122.

14. Mamba KC, Muula AS, Stones W. Facility-imposed barriers to early utilization of focused antenatal care services in Mangochi district, Malawi-a mixed methods assessment. BMC pregnancy and childbirth. 2017;17(1):444.

15. Beyamo A, Facha W, Lire A. Focused antenatal care service utilization and associated factors in damot sore district, southern ethiopia, community based cross sectional study. American Journal of Health Research. 2017;5(6):167-72.

16. Ayalew TW, Nigatu AM. Focused antenatal care utilization and associated factors in Debre Tabor Town, northwest Ethiopia, 2017. BMC research notes. 2018 Dec;11(1):819.

17. Getachew T, Abajobir AA, Aychiluhim M. Focused antenatal care service utilization and associated factors in Dejen and Aneded districts, Northwest Ethiopia. Primary Health Care. 2014;4(4):21671079.

18. Chorongo D, Okinda FM, Kariuki EJ, Mulewa E, Ibinda F, Muhula S, Kimathi G, Muga R. Factors influencing the utilization of focused antenatal care services in Malindi and Magarini sub-counties of Kilifi county, Kenya. The Pan African medical J. 2016;25(Suppl 2).

19. Muchie KF. Quality of antenatal care services and completion of four or more antenatal care visits in Ethiopia: a finding based on a demographic and health survey. BMC pregnancy and childbirth. 2017;17(1):300.

Cite this article as: Sunkad MA, Kadakol R, Shetty D, Javali SB, Dhamankar S. Focussed antenatal care a possible opportunity towards safe motherhood. Int J Reprod Contracept Obstet Gynecol 2019;8:3245-9. 